\title{
Dopamine: A Marker of Psychosis and Final Common Driver of Schizophrenia Psychosis
}

ur attempt to understand schizophrenia in neurochemical terms began with the landmark studies of Carlsson and Lindqvist (1) in the 1960s. The results of these studies, based on the action of chlorpromazine, were strengthened by the binding studies carried out in both Seeman's (2) and Synder's (3) laboratories, which showed that antipsychotic potency was correlated with dopamine $\mathrm{D}_{2}$ receptor binding. The one major exception to this correlation is clozapine, which appears to be the most effective available drug for treating schizophrenia symptoms. The most recent version of the resulting dopamine hypothesis suggests that genetic, environmental, and developmental variables play major etiological roles in schizophrenia, but that striatal dopamine presynaptic overactivity remains the final trigger resulting in psychosis.

The severity and chronicity of schizophrenia have fueled efforts to identify individuals at risk for schizophrenia, with the assumption that a variety of psychosocial and medical treatments can mitigate the longitudinal course (3). Criteria for high-risk individuals and early intervention programs have been developed, and a discussion about including psychosis risk syndrome in DSM-5 $(4,5)$ has generated a lively debate. The basis of this debate is that many early intervention programs advocate the use of antipsychotic medications along with psychosocial support. The risk of metabolic side effects in high-risk individuals who do not go on to develop the full disorder violates the basic principle of medical treatment, "First, do no harm." A Cochrane Review (6) of the treatment of high-risk individuals finds insufficient evidence of benefit thus far and suggests further study.

The article by Howes et al. (7) in this issue of the Journal details a prospective study involving a group of 30 subjects with prodromal symptoms who fall into an ultra-high-risk category for developing schizophrenia. These patients lacked only active psychotic symptoms to qualify for a diagnosis of schizophrenia and to become regular candidates for antipsychotic medication. Using $\left[{ }^{18} \mathrm{~F}\right] \mathrm{DOPA}$ in a

"Can such a screen be used to more safely start treating prodromal patients with antipsychotic drugs by identifying those who would convert and treating them selectively?" positron emission tomography study, the authors were able to show that on average, the patients with the highest levels of dopamine in the associative area of the striatum were those who converted to active schizophrenia. Increased dopamine synthesis is seen only in those who convert to expressing psychotic symptoms, thus qualifying for a diagnosis of schizophrenia. First, this finding adds to the evidence that dopamine overactivity is the central factor driving the full manifestation of psychosis. This may not be specific for schizophrenia, since one of the six patients who converted to schizophrenia in the Howes et al. study went on to develop a bipolar illness, but it held for all five of those who converted to active schizophrenia. Second, it raises the question: Can such a screen be used to more safely start treating prodromal patients with antipsychotic drugs by identifying those who would convert and treating them selectively?

These data strongly support the hypothesis that dopamine overactivity, specifically in the striatum, is strongly associated with the emergence of psychotic symptoms and that overactive dopamine release in the striatum is the proximal cause of psychotic symptoms. This provides the strongest evidence to date that dopamine overactivity is essential for psychosis; however, the data still leave some questions unanswered. The most 
pressing is the role of dopamine in schizotypal individuals, who as a group showed dopamine levels as high as those who converted to full psychosis without a single conversion to a psychotic state.

The research on ultra-high-risk cohorts, which includes many studies featuring significant psychosocial or cognitive-behavioral treatment, indicates that between $15 \%$ and $40 \%$ of individuals convert to schizophrenia (8). Over the past 15 years, a growing effort has gone into attempting to refine the ultra-high-risk diagnosis and prevent the onset of schizophrenia in groups with high-risk symptoms (8). Nonetheless, a recent article by Addington et al. (9) in the Journal showed that over 2 years, patients who did not convert actually improved slightly without medication. These results suggest that the diagnostic validity of the ultra-high-risk syndrome is not precise enough to begin treatment with drugs that show significant metabolic side effects; in many people, drug treatment may not be necessary. What is needed is a marker that identifies people who will convert to full psychosis and in whom treatment can be expected to prevent the development of schizophrenia. The Howes et al. study, perhaps combined with anatomical regression data or EEG spectral power studies $(10,11)$, may present us with a reliable test battery for predicting conversion to active schizophrenia.

This marker needs to be verified; the methodological problems with schizotypal personality disorders need further follow-up; and the cost-benefit analysis of testing (using multiple test modalities) and treating these patients needs to be assessed before final diagnosis and treatment recommendations are formulated. However, we now have a tool that, although costly and limited in its availability, appears to be able, with considerable accuracy, to identify those patients who will convert to full psychosis. This study will require replication and a detailed cost-benefit analysis before the recommendation can be made to examine patients who present with ultra-high-risk symptoms; however, it provides a potential vehicle for getting treatment to those who will benefit and protecting those who will not from a potentially harmful course of treatment.

\section{References}

1. Carlsson A, Lindqvist M: Effect of chlorpromazine or haloperidol on formation of 3-methoxytyramine and normetanephrine in mouse brain. Acta Pharmcol Toxicol 1963; 20:140-144

2. Seeman P, Lee T: Antipsychotic drugs direct correlation between clinical potency and presynaptic action on dopamine neurons. Science 1975; 188:1217-1219

3. Creese I, Burt DR, Snyder SH: Dopamine receptor binding predicts clinical and pharmacological potencies of antischizophrenic drugs. Science 1976; 192:481-483

4. Carpenter WT: Anticipating DSM: should psychosis risk become a diagnostic class? Schizophr Bull 2009; 35:841-843

5. Woods SW, Walsh BC, Saksa JR, McGlashan TH: The case for including attenuated psychotic symptoms syndrome in DSM-5 as a psychosis risk syndrome. Schizophr Res 2010; 123:199-207

6. Marshall M, Rathbone J: Early intervention for psychosis. Cochrane Database Syst Rev 2011; 6:CD004718

7. Howes OD, Bose SK, Turkheimer F, Valli I, Egerton A, Valmaggia LR, Murray RM, McGuire P: Dopamine synthesis capacity before onset of psychosis: a prospective $\left[{ }^{18} \mathrm{~F}\right]$-DOPA PET imaging study. Am J Psychiatry 2011; 168:1311-1317

8. Yung AR, Yuen HP, Berger G, Francey S, Hunag TC, Nelson B, Phillips L, McGorry P: Declining transition rate in ultra high risk (prodromal) services: dilution or reduction of risk. Schizophr Bull 2007; 33:673-681

9. Addington J, Cornblatt BA, Cadenhead KS, Cannon TD, McGlashan TH, Perkins DO, Seidmn LJ, Tsuang MT, Walker EF, Woods SW, Heinssen R: At clinical high risk for psychosis: outcome for nonconverters. Am J Psychiatry 2011; 168:800-805

10. Koutsouleris N, Gaser C, Bottlender R, Davatzikos C, Decker P, Jager M, Schmitt G, Reiser M, Moeller H-J, Meisenzahl EM: Use of neuroanatomical pattern regression to predict the structural brain dynamics of vulnerability and transition to psychosis. Schizophr Res 2010; 123:175-187

11. Zimmermann R, Gschwandtner U, Wilhelm FH, Pflueger MO, Riecher-Röessler A, Fuhr P: EEG spectral power and negative symptoms in at-risk individuals predict transition to psychosis. Schizophr Res 2010; 123:217-224

FRITZ A. HENN, M.D., PH.D.

From the Cold Spring Harbor Laboratory, Cold Spring Harbor, N.Y. Address correspondence to Dr. Henn (fhenn@cshl.edu).Editorial accepted for publication September 2011 (doi: 10.1176/appi.ajp.2011.11091346).

Dr. Henn is funded by Simon's Foundation and is a consultant to AstraZeneca. Dr. Freedman has reviewed this editorial and found no evidence of influence from these relationships. 